\title{
Study on Optimization of Geothermal Tail Water Reinjection Process in Moderately Deep Sandstone
}

\author{
Hongyan Li, ${ }^{1}$ Pengtao Wang $\mathbb{D}^{1},{ }^{1}$ Bin Liu, ${ }^{1}$ Xianyu Zhang, ${ }^{1}$ Shiyan Guo, ${ }^{1}$ Hui Xiao, ${ }^{2}$ \\ and Hai Huang ${ }^{2}$ \\ ${ }^{1}$ Sinopec Green Source Thermal Energy Development Co., Ltd., Xianyang 712000, China \\ ${ }^{2}$ Shaanxi Key Laboratory of Advanced Stimulation Technology for Oil \& Gas Reservoirs, Xi'an Shiyou University, \\ Xi'an 710065, China
}

Correspondence should be addressed to Pengtao Wang; wangpengtao0224@sina.com

Received 11 November 2020; Revised 23 December 2020; Accepted 24 January 2021; Published 11 February 2021

Academic Editor: Zhigang Tao

Copyright ( 2021 Hongyan Li et al. This is an open access article distributed under the Creative Commons Attribution License, which permits unrestricted use, distribution, and reproduction in any medium, provided the original work is properly cited.

\begin{abstract}
The existing test methods of geothermal tail water reinjection effect in sandstone geothermal reservoirs are not suitable for moderately deep and deep sandstone geothermal reservoirs, resulting in the poor filtration performance of fine-grained reservoirs. Therefore, a test method for the geothermal tail water reinjection effect in a moderately deep sandstone geothermal reservoir is proposed. This paper studies the static compatibility of raw water and geothermal tail water under different mixing ratios, determines the indexes affecting the reinjection effect of moderately deep sandstone geothermal reservoir tail water, analyzes the weight set of each influencing factor, and formulates a test standard for the reinjection effect of geothermal reservoir tail water. Finally, a tracer is selected to trace the reinjected tail water in the geothermal reservoir, and the tracer is used to obtain the result of each previously determined index. Eventually, the final reinjection effect of the geothermal tail water is obtained. The experimental results show that the fine-grade filtration performance, silt-grade filtration performance, and coarse-grade filtration performance of this method are improved compared with those of other methods; thus, the particle filtration performance is better, and the reinjection effect of geothermal reservoir tail water is better, which has a great significance for the geothermal resource exploitation of moderately deep sandstone.
\end{abstract}

\section{Introduction}

In China, the exploration of geothermal resources, which can effectively alleviate environmental pollution and energy shortages, has mainly concentrated on moderately deep sandstone reservoirs (the buried depth is $200 \mathrm{~m}-3000 \mathrm{~m}$ ) [1, $2]$. However, in the exploration of geothermal resources in moderately deep sandstone reservoirs, challenges such as the gradual expansion of the geothermal descending funnel area arise, and the overexploitation of moderately deep sandstone in some areas brings about a series of problems such as the forced change in the geothermal environment, increased costs of heat transfer, imbalance of the hydrological budget, and decline of the dynamic water level [3-5].

In order to solve the above problems, sandstone thermal reservoir tail water injection is the most effective way [6-9]. Many geothermal field surveys indicate that $80 \%$ of the pore-type thermal storage injection well plugging part of the injection wells was forced to halt [10]. Gallp thinks silicate scale such as is common in the world's most geothermal field in the medium $\mathrm{pH}$ and medium total soluble solids of geothermal field is especially striking [11]; Mackay finds that sulfate scale leads to clogging of geothermal water injection in Brazil North Sea geothermal field [12]. Testing the reinjection effect is the key step in achieving reinjection of geothermal tail water. At present, research on the testing of reinjection of geothermal tail water has generally developed outside of China and has mainly focused on the well location layout, well network optimization, well spacing, reinjection temperature, reinjection process, and reinjection mode. Based on a large amount of heat flow data, the geothermal resources of dry hot rocks in mainland China are evaluated [13-16]. Large-scale karst heat storage is utilized to develop modular heating and geothermal energy storage technology, 
TABLE 1: Simulation results of total precipitation after mixed simulation of raw water and heat storage tail water.

\begin{tabular}{lccc}
\hline Number & $\begin{array}{c}\text { Raw water mix } \\
\text { proportion }\end{array}$ & $\begin{array}{c}\text { Heat storage tail } \\
\text { water mixing ratio }\end{array}$ & $\begin{array}{c}\text { Total precipitation } \\
(\mathrm{g} / \mathrm{kg})\end{array}$ \\
\hline 1 & 10 & 0 & 0.118 \\
2 & 8 & 2 & 0.102 \\
3 & 6 & 4 & 0.092 \\
4 & 5 & 5 & 0.082 \\
5 & 4 & 6 & 0.078 \\
6 & 2 & 8 & 0.065 \\
7 & 0 & 10 & 0.049 \\
\hline
\end{tabular}

forming a new "Geothermal+" clean energy utilization pattern that considers geothermal energy as well as other forms of energy [17]. Thomson heat reservoir is discussed such as oxidation-reduction and chemical process such as acid-base reaction of carbonate precipitation [18]. Combining tracer test, based on the mobile asymptote method, puts forward the theory of thermal storage parameter inversion model to forecast the water temperature changes in the wells of mining and influence the mining $[19,20]$. Some scholars think particle migration affected by injection velocity and reservoir property, temperature, and pressure are the main controlling factors of suspended solids jams [21, 22]; Liu et al. [23] think under the condition of mass injection, hot breakthrough is inevitable and must work hard to recharge engineering study reasonable well spacing of mining irrigation, which is necessary to prevent thermal breakthrough in a short period of time.

However, there is the problem of poor filtration performance of granular sieves in these methods. A new process of recharging tail water from medium and deep sandstone thermal storage was proposed in this paper. The key point is mixing the simulated raw water and geothermal tail water, testing the reinjection effect of moderately deep sandstone geothermal tail water according to the index and standard evolved, and confirming the changes in the subsidence at the well, thereby determining the effect of reinjection of geothermal tail water.

\section{The Test Method of Reinjection of Geothermal Tail Water in Moderately Deep Sandstone}

2.1. The Mixing Ratio of Raw Water and Geothermal Tail Water. Firstly, the static compatibility of raw water and geothermal tail water was studied under different mixing ratios. The mixing of raw water and geothermal tail water was performed for seven mixing ratios: one of which is $10: 0$, which mainly simulates the process of the chemical reaction of the raw water in the geothermal reservoir, and another is $0: 10$, which mainly simulates the hydrochemical reaction before the mixing of raw water and geothermal tail water. In the simulation of the mixing of raw water and geothermal tail water, the initial temperature of the raw water is $76^{\circ} \mathrm{C}$, and the geothermal tail water is $36^{\circ} \mathrm{C}$. The deposition simulation result after the mixing of raw water and geothermal tail water is shown in Table 1. The amount of deposition is shown in Table 2.

2.2. Test Index and Standard. According to the deposition of raw water and geothermal tail water, the 9 indexes that affect the effect of geothermal tail water in moderately deep sandstone reservoirs are shown in Table 3.

Confirming the index weight set that affects the effect of geothermal tail water in moderately deep sandstone, the expression is as follows:

$$
X=\left(x_{1}, x_{2}, x_{3}, \cdots, x_{g}\right) .
$$

Among them, $X$ represents the weight set of the impact index, and $x$ represents the index that affects the effect of reinjection of geothermal tail water in moderately deep sandstone.

According to the weight set of the impact index, the test standard of the reinjection effect of geothermal tail water in moderately deep sandstone is formulated. The test standard of the reinjection effect of geothermal tail water is shown in Table 4.

2.3. Method to Test the Reinjection Effect of Geothermal Tail Water in Sandstone. To test the reinjection effect of geothermal tail water in moderately deep sandstone according to the established indexes and standards, one tracer was selected for reinjection into the geothermal reservoir with the geothermal tail water. Tracers can monitor some data of the indexes when following the fluid, test the other data of the indexes by sampling, and evaluate the reinjection effect based on these data [24-27]. The reinjection effect was eventually obtained according to the comprehensive test results. The selected tracer was ammonium rhodanate, and the reagent characteristics are shown in Table 5.

Tracer selection must follow the following principles: (1) low volatile background value in the geothermal reservoir; (2) no or low adsorption of the tracer in the geothermal surrounding rocks; (3) to meet the accuracy requirement, high detection sensitivity is required when the detection limit is lower than or close to the background value of the environment; (4) the tracer has a favorable chemical and thermal stability in certain circumstances and is easy to dissolve in water and is compatible with formation water; (5) the tracer has no or extremely short-term adverse effects on the environment; (6) the tracer is inexpensive and results in a low testing cost. Tracers also need to be nonpoisonous, safe, environmentally friendly, reasonably priced, operational in the field, and economical. Preliminary testing of the selected tracers was carried out to test their thermal stability and compatibility to ensure that they are suitable for harvesting and irrigation well systems.

The formula for calculating the required quantity of ammonium rhodanate is as follows:

$$
G=\pi \times R^{2} \times H \times \alpha \times \beta \times C_{\mathrm{p}}
$$


TABLE 2: Precipitation of precipitated minerals.

\begin{tabular}{|c|c|c|c|c|}
\hline Number & Types of precipitated minerals & Raw water mix proportion & Heat storage tail water mixing ratio & Precipitation $(\mathrm{g} / \mathrm{kg})$ \\
\hline \multirow{7}{*}{1} & \multirow{7}{*}{$\begin{array}{c}\text { Precipitation calcite dolomite } \\
\text { White mica } \\
\text { Pyrite } \\
\text { Precipitation calcite dolomite } \\
\text { White mica }\end{array}$} & 10 & 0 & $8.03 E-02$ \\
\hline & & 8 & 2 & $5.08 E-02$ \\
\hline & & 6 & 4 & $3.09 E-02$ \\
\hline & & 5 & 5 & $3.15 E-02$ \\
\hline & & 4 & 6 & $2.07 E-02$ \\
\hline & & 2 & 8 & $2.05 E-02$ \\
\hline & & 0 & 10 & $1.04 E-02$ \\
\hline \multirow{7}{*}{2} & \multirow{7}{*}{$\begin{array}{c}\text { Pyrite } \\
\text { Precipitation calcite dolomite } \\
\text { White mica } \\
\text { Pyrite } \\
\text { Precipitation calcite dolomite }\end{array}$} & 10 & 0 & $1.05 E-02$ \\
\hline & & 8 & 2 & $2.10 E-02$ \\
\hline & & 6 & 4 & $2.04 E-02$ \\
\hline & & 5 & 5 & $2.25 E-02$ \\
\hline & & 4 & 6 & $1.90 E-02$ \\
\hline & & 2 & 8 & $0.90 E-02$ \\
\hline & & 0 & 10 & $0.00 E-02$ \\
\hline \multirow{7}{*}{3} & \multirow{7}{*}{$\begin{array}{c}\text { White mica } \\
\text { Pyrite } \\
\text { Precipitation calcite dolomite } \\
\text { White mica } \\
\text { Pyrite } \\
\text { Precipitation calcite }\end{array}$} & 10 & 0 & $0.05 E-02$ \\
\hline & & 8 & 2 & $0.04 E-02$ \\
\hline & & 6 & 4 & $0.03 E-02$ \\
\hline & & 5 & 5 & $0.00 E-02$ \\
\hline & & 4 & 6 & $0.00 E-02$ \\
\hline & & 2 & 8 & $0.00 E-02$ \\
\hline & & 0 & 10 & $0.00 E-02$ \\
\hline \multirow{7}{*}{4} & \multirow{7}{*}{ Dolomite } & 10 & 0 & $0.10 E-02$ \\
\hline & & 8 & 2 & $0.10 E-02$ \\
\hline & & 6 & 4 & $0.05 E-02$ \\
\hline & & 5 & 5 & $0.05 E-02$ \\
\hline & & 4 & 6 & $0.05 E-02$ \\
\hline & & 2 & 8 & $0.05 E-02$ \\
\hline & & 0 & 10 & $0.00 E-02$ \\
\hline \multirow{7}{*}{5} & & 10 & 0 & $2.05 E-02$ \\
\hline & & 8 & 2 & $2.50 E-02$ \\
\hline & & 6 & 4 & $2.80 E-02$ \\
\hline & Chalcedony & 5 & 5 & $2.90 E-02$ \\
\hline & & 4 & 6 & $2.95 E-02$ \\
\hline & & 2 & 8 & $3.15 E-02$ \\
\hline & & 0 & 10 & $3.20 E-02$ \\
\hline
\end{tabular}

where $G$ represents the quantity of ammonium rhodanate, $R$ represents the radius of influence, $H$ represents the actual thickness of the water-bearing stratum in the geothermal reservoir, $\alpha$ represents the dispersion constant factor, which is generally $0.0153, \beta$ represents the advantage correction factor of the flow concentration field, and $C_{p}$ represents the peak concentration of ammonium rhodanate.

Two ponds, each with a size of $1.6 \times 2 \times 2 \mathrm{~m}^{3}$, were dug approximately five meters from the reinjection well before ammonium rhodanate was released. The bottom and perim- eter of the ponds were sealed with cement, the ammonium rhodanate was dissolved, the solution was mixed, the concentration was tested constantly to ensure that it met the standard, and the solution was injected into the well with the reinjection tail water. Water samples were collected every two days at 10 a.m. and 5 p.m. When the concentration of the testing sample was higher than the background value, the frequency was increased to 3 times a day. The content of the tracer ions was determined according to spectrophotography, the change curve of the concentration of the tracer 
TABLE 3: Index influencing the effect of reinjection of heat storage tail water in sandstone.

\begin{tabular}{|c|c|c|}
\hline Number & Index name & Specific content of indicators \\
\hline 1 & Permeability & $\begin{array}{c}\text { The capacity and permeability of fluid in thermal reservoir are directly } \\
\text { related to the reinjection rate }\end{array}$ \\
\hline 2 & Effective porosity & The volume ratio of pores to rocks \\
\hline 3 & Sand thickness ratio & $\begin{array}{l}\text { Specific thickness ratio of sandstone and stratum in the middle and deep } \\
\text { layers of the thermal reservoir }\end{array}$ \\
\hline 4 & Sand thickness & Actual thickness of aquifer \\
\hline 5 & Argillaceous content & Total content of mud in reinjection \\
\hline 6 & Maximum single layer thickness & Maximum thickness of a single layer in reinjection \\
\hline 7 & Cementation degree & Concrete degree of sediment cementation \\
\hline 8 & Particle size classification & Grade of sediment particle diameter \\
\hline 9 & Flow & Amount of fluid passing through a certain period of time in thermal storage \\
\hline 10 & Drawdown rate of water level & Actual rate of water level drop in thermal storage \\
\hline
\end{tabular}

TABLE 4: Test standard of reinjection effect of heat storage tail water in sandstone.

\begin{tabular}{|c|c|c|c|c|c|}
\hline \multirow{3}{*}{$\begin{array}{l}\text { Standard permeability } \\
\text { Effective porosity }\end{array}$} & \multicolumn{5}{|c|}{ Weight } \\
\hline & 1 & 3 & $5 \quad 6$ & \multirow{2}{*}{${ }^{7}$ Preferable ${ }^{8}$} & 9 \\
\hline & $\mathrm{Bad}$ & Poor & Common & & Good \\
\hline Sand thickness ratio & $\begin{array}{l}\text { Less than } \\
50 \mathrm{md}\end{array}$ & $\begin{array}{l}50 \text { to } \\
100 \mathrm{md}\end{array}$ & $\begin{array}{l}100 \text { to } \\
200 \mathrm{md}\end{array}$ & $\begin{array}{l}200 \text { to } \\
300 \mathrm{md}\end{array}$ & Greater than $300 \mathrm{md}$ \\
\hline Sand thickness & Less than 5 & 5 to 10 & 10 to 15 & 15 to 20 & Greater than 20 \\
\hline Argillaceous content & Less than 10 & 10 to 20 & 20 to 30 & 30 to 40 & More than 40 \\
\hline $\begin{array}{l}\text { Maximum single layer } \\
\text { thickness }\end{array}$ & $\begin{array}{l}\text { Less than } \\
200 \mathrm{~cm}\end{array}$ & $\begin{array}{l}200 \text { to } \\
300 \mathrm{~cm}\end{array}$ & $\begin{array}{l}300 \text { to } \\
400 \mathrm{~cm}\end{array}$ & $\begin{array}{l}400 \text { to } \\
500 \mathrm{~cm}\end{array}$ & Over $500 \mathrm{~cm}$ \\
\hline Cementation degree & Over $20 \mathrm{~kg}$ & 15 to $20 \mathrm{~kg}$ & 10 to $15 \mathrm{~kg}$ & 5 to $10 \mathrm{~kg}$ & Less than $5 \mathrm{~kg}$ \\
\hline $\begin{array}{l}\text { Particle size } \\
\text { classification }\end{array}$ & $\begin{array}{l}\text { Less than } \\
5 \mathrm{~cm}\end{array}$ & 5 to $10 \mathrm{~cm}$ & 10 to $15 \mathrm{~cm}$ & 15 to $20 \mathrm{~cm}$ & Over $20 \mathrm{~cm}$ \\
\hline Flow & Compact & - & Loose & - & Loose \\
\hline Standard & $\begin{array}{l}\text { Fine to } \\
\text { medium } \\
\text { sandstone } \\
\text { less than } \\
2.5 \mathrm{~mm}\end{array}$ & - & $\begin{array}{c}\text { Coarse } \\
\text { sandstone } \\
\text { about } \\
2.5 \mathrm{~mm}\end{array}$ & - & $\begin{array}{l}\text { Gravel larger } \\
\text { than } 2.5 \mathrm{~mm}\end{array}$ \\
\hline Permeability & Nonartesian & $\begin{array}{l}\text { Less than } \\
50 \mathrm{~m}^{3} / \mathrm{S}\end{array}$ & $\begin{array}{c}50 \text { to } \\
100 \mathrm{~m}^{3} / \mathrm{S}\end{array}$ & $\begin{array}{c}150 \text { to } \\
250 \mathrm{~m}^{3} / \mathrm{S}\end{array}$ & Over $250 \mathrm{~m}^{3} / \mathrm{s}$ \\
\hline $\begin{array}{l}\text { Drawdown rate } \\
\text { of water level }\end{array}$ & Strong & - & Weak & - & - \\
\hline
\end{tabular}

TABLE 5: Characteristics of selected tracer.

\begin{tabular}{lcc}
\hline Number & Performance & Data \\
\hline 1 & Name & Ammonium thiocyanate \\
& Features & The test method is \\
& relatively simple \\
2 & Background concentration & Lof heat storage \\
Performance & Name & Less adsorption \\
& Features & Good thermal stability \\
& Background concentration & High solubility \\
& of heat storage & $0.45 \mathrm{mg} / \mathrm{L}$ \\
\hline
\end{tabular}

was drawn, the changes were observed, the times when the concentration peaked and when the tracer reached the mining well were obtained, and the changes in the precipitate in the well were determined, thus obtaining the effect of the reinjection of geothermal tail water.

\section{Experiment}

3.1. Testing Procedure. A comparative test is carried out on the test method of the reinjection of geothermal reservoir tail water in the designed moderately deep sandstone, taking the data on a reinjection procedure in certain moderately deep sandstone as a sample. The reinjection data are shown in Table 6. 
TABle 6: Reinjection data.

\begin{tabular}{|c|c|c|c|c|c|}
\hline Project & Well 1 & Well 2 & Well 3 & Well 4 & Well 5 \\
\hline Well radius & $0.113 \mathrm{~m}$ & $0.113 \mathrm{~m}$ & $0.113 \mathrm{~m}$ & $0.113 \mathrm{~m}$ & $0.113 \mathrm{~m}$ \\
\hline Thickness of intake section & $96 \mathrm{~m}$ & $96 \mathrm{~m}$ & $96 \mathrm{~m}$ & $96 \mathrm{~m}$ & $96 \mathrm{~m}$ \\
\hline Actual buried depth of static water level & $127.28 \mathrm{~m}$ & $127.28 \mathrm{~m}$ & $127.28 \mathrm{~m}$ & $127.28 \mathrm{~m}$ & $127.28 \mathrm{~m}$ \\
\hline Recovery value after water level correction & $16.34 \mathrm{~m}$ & $21.1 \mathrm{~m}$ & $62.3 \mathrm{~m}$ & $76.3 \mathrm{~m}$ & $105.22 \mathrm{~m}$ \\
\hline Buried depth after correction of stable dynamic water level & $111.48 \mathrm{~m}$ & $107.18 \mathrm{~m}$ & $67.05 \mathrm{~m}$ & $57.64 \mathrm{~m}$ & $26.13 \mathrm{~m}$ \\
\hline Stable irrigation capacity & $38 \mathrm{~m}^{3} / \mathrm{h}$ & $61 \mathrm{~m}^{3} / \mathrm{h}$ & $81 \mathrm{~m}^{3} / \mathrm{h}$ & $93 \mathrm{~m}^{3} / \mathrm{h}$ & $101 \mathrm{~m}^{3} / \mathrm{h}$ \\
\hline
\end{tabular}

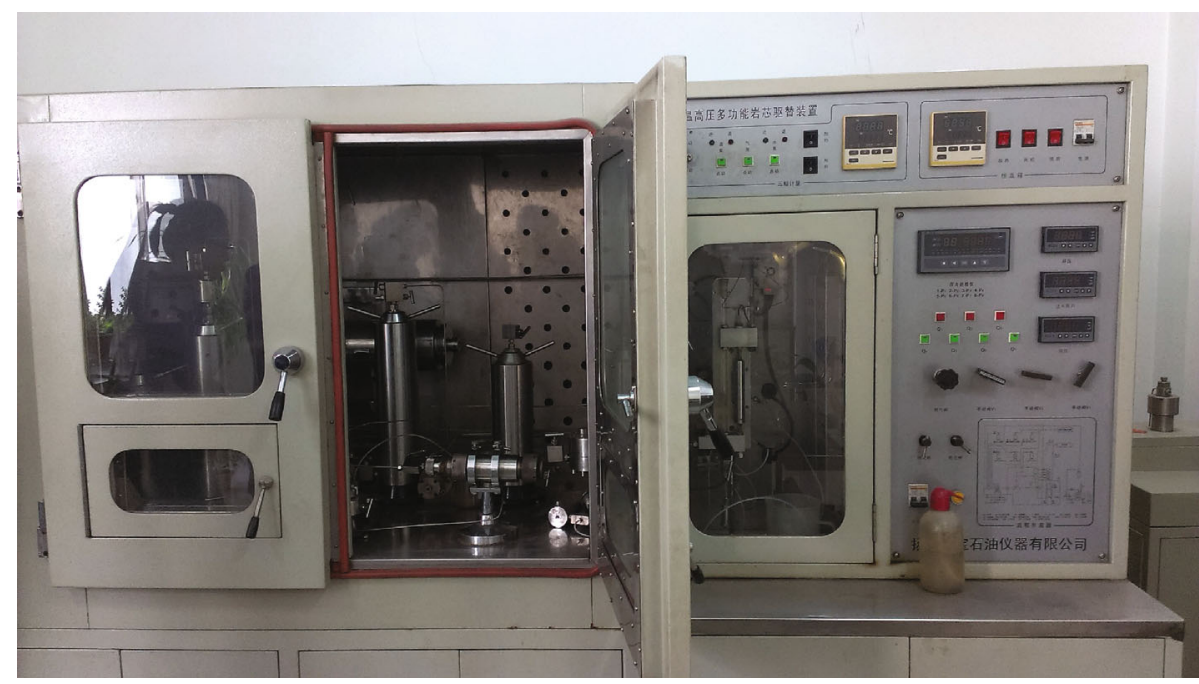

FIGURE 1: Experimental apparatus used in the experiment.

Experimental sampling of the project was carried out after reinjection, in which the experimental raw water was taken from the geothermal reservoir water sample in well no. 1 of the project. However, the experimental geothermal tail water samples were taken from well no. 3 of this project after heat exchange. The experimental apparatus used in this experiment is shown in Figure 1.

With this device, the displacement pressure was regulated by an advection pump, and the confining pressure was carried out by a ring pressure pump. Flow rate regulation was achieved through the no. 2 advection pump. Sample determination was performed using the experimental apparatus.

3.2. Testing Index. The reinjection effect is affected by the geological condition, construction quality of the reinjection well, parameters of the reinjection well, running condition of the precipitation reinjection, and so on; however, the amount of filtration, which is also called the filtering effect, is determined by the actual reinjection amount. When the filtration effect is good, some microorganisms can also be filtered out, which can effectively prevent physical blockage during reinjection in the well and guarantee the effect of the reinjection. They complement each other. Therefore, we obtained the reinjection effect of geothermal tail water in moderately deep sandstone according to the results of the sample test. The filtration performance of the granular sieve was obtained according to the testing result, includ- ing the fine-grade sieve filtration performance, silt-grade sieve filtration performance, and coarse-grade sieve filtration performance.

To ensure that the results of this experiment are comparable with the methods of literature [12] and literature [13], comparative experiments are performed, and the experimental data of the filtration performance of the granular sieves were obtained as comparative experimental data to test the effect of reinjection of geothermal tail water in moderately deep sandstone.

The comparison of these three testing methods of the filtration performance of granular sieves is achieved by comparing the testing data of the fine-grade sieve filtration performance, silt-grade sieve filtration performance, and coarse-grade sieve filtration performance among those three testing methods. The filtration performance of the finegrade sieve is excellent, and that of the silt-grade and coarse-grade sieves is good.

3.3. Testing Result. The diagram of the reinjection effect of geothermal tail water in moderately deep sandstone is shown in Figure 2.

As shown in Figure 2, the whole reinjection system remains sealed. When hot water is developed from the geothermal reservoir, it will be reinjected into the reservoir via the recycling system of the sealed pipeline after exchanging heat, making full use of the energy of the geothermal 


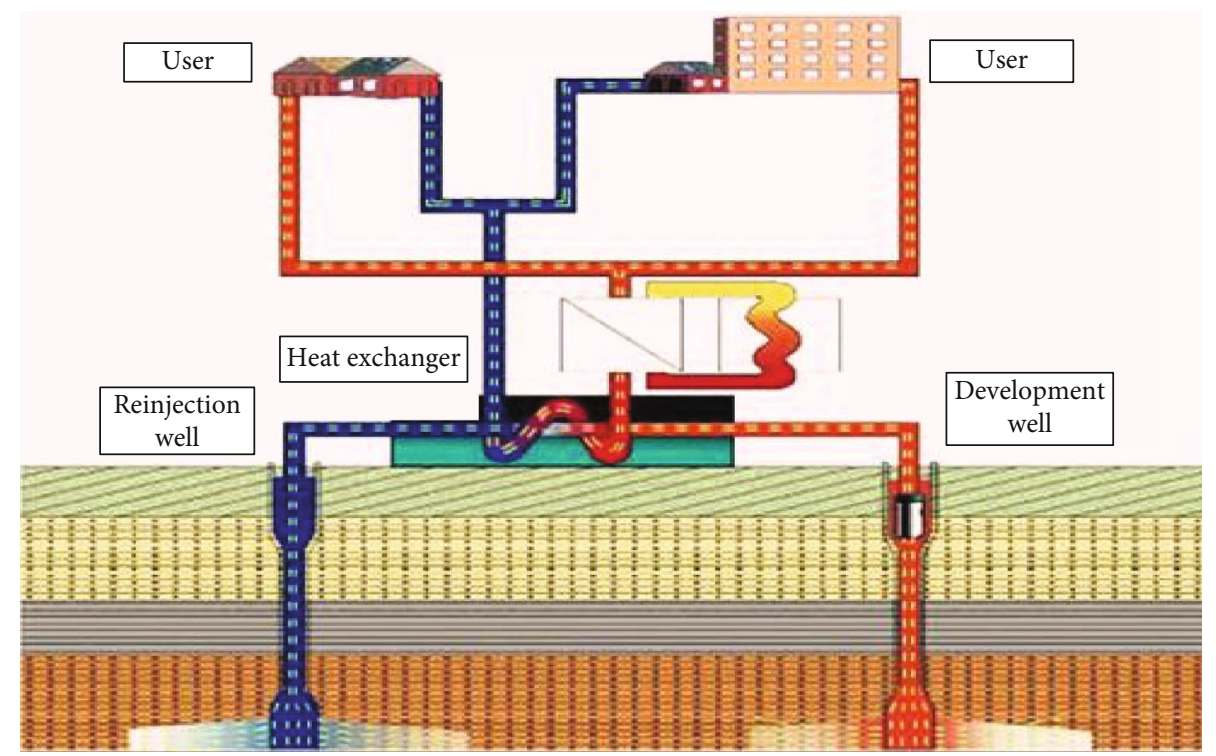

FIGURE 2: Diagram of reinjection effect of heat storage tail water in medium deep sandstone.

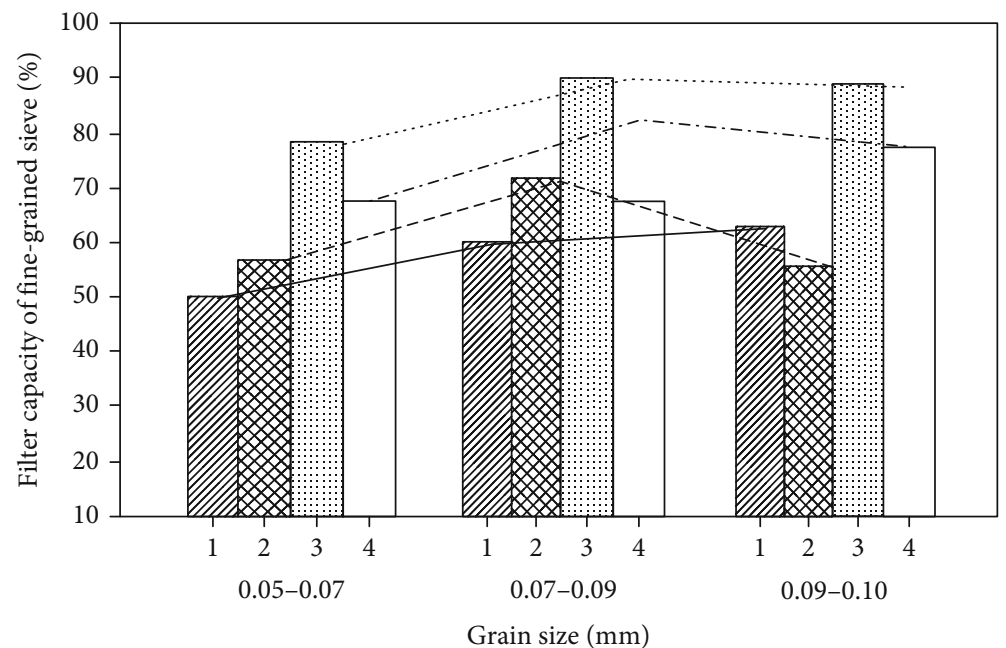

$\square$ Literature [2]
$\square$ Literature [3] [4]

FIGURE 3: Testing result of fine-grained sieve filter performance.

reservoir, avoiding pollution, and ensuring the stability of the water quality and reinjection effect. The methods of this paper and the comparative results of the filtration performance of fine-grained sieves in other literature are shown in Figure 3.

According to the test result of fine-grained sieve filtration performance in Figure 2, we can see that the sieve filtration rate of the designed method for reinjection of geothermal tail water in moderately deep sandstone can reach $78.2 \%, 89.6 \%$, and $88.2 \%$ when the particle sizes are $0.05 \sim 0.07,0.07 \sim 0.09$, and $0.09-0.10$, and the sieve filtration rate is always the highest among the several experimental methods tested. The rate is $49.9 \%, 59.8 \%$, and $53.9 \%$ when the particle sizes are $0.05 \sim 0.07,0.07 \sim 0.09$, and 0.09-0.10, respectively, with the method from literature [16], which resulted in the lowest fil- tration rates among the experimental methods tested. The rates with the method from literature [17] are $58.1 \%$, $71.9 \%$, and $57.2 \%$ when the particle sizes are $0.05 \sim 0.07$, 0.07 0.09, and 0.09 0.10. The designed method described in this paper is proven to be the most effective method for the $h$ reinjection of geothermal tail water in moderately deep sandstone.

The filtration performance results of the silt-grade sieve using the method described in this paper and the other methods are shown in Figure 4.

According to the filtration performance results of the siltgrade sieve, the filtration rate of the designed method for reinjection of geothermal tail water can reach $84.1 \%, 94.9 \%$, and $82.1 \%$ when the particle sizes are $0.05 \sim 0.07,0.07 \sim 0.09$, and $0.09 \sim 0.10$, and the sieve filtration rate is always the 


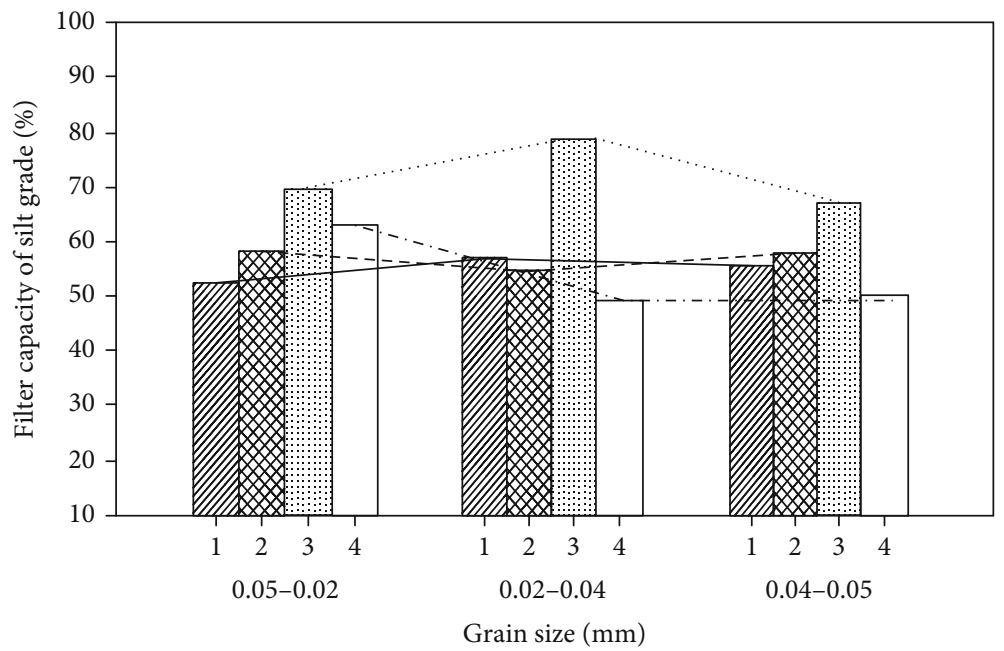

WIIIs Literature [2]

$\square$ Literature [4]

Literature [3]

in: Methods of this paper

FIgURE 4: Experimental results on silt-grade sieve filter performance.

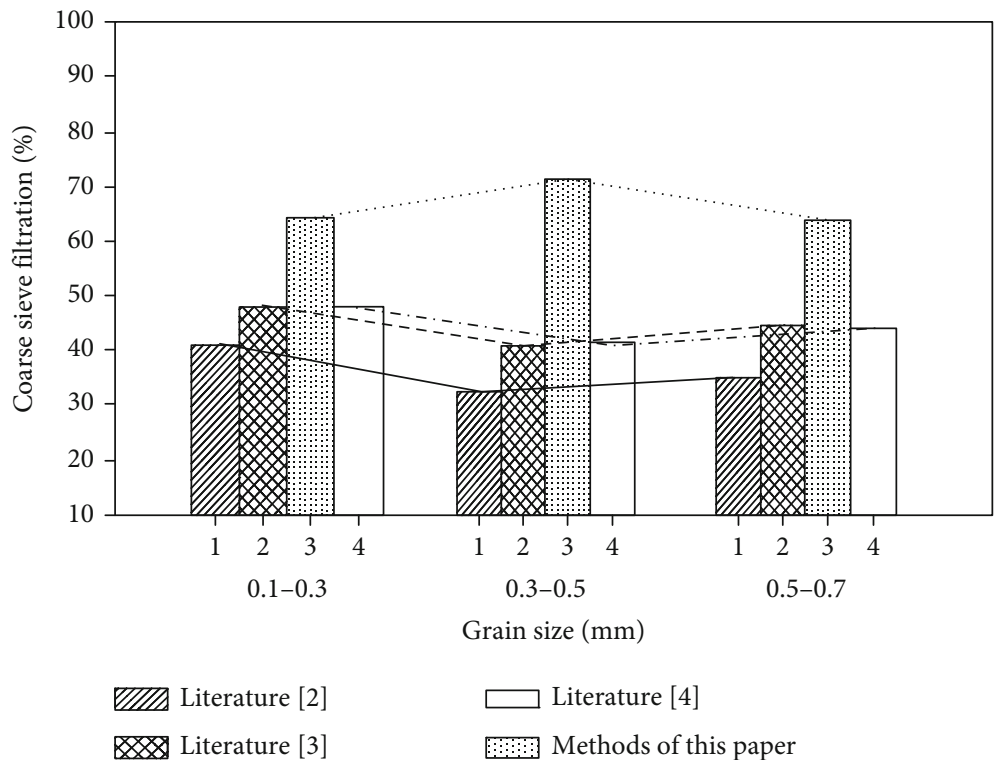

Figure 5: Experimental results on coarse-grade sieve filter performance.

highest among the results of the several experimental methods tested, which means that this method can filter out the silt-grade sieve effectively. Thus, the designed method described in this paper is the most effective method for filtering silt-grade precipitates.

The filtration performance results of the coarse-grade sieve using the method described in this paper and the others are shown in Figure 5.

According to the experimental results of the coarse-grade sieve filtration performance shown in Figure 5, the filtration rate of the designed method for the reinjection of geothermal tail water can reach $67.8 \%, 73.8 \%$, and $77.1 \%$ when the particle sizes are 0.05-0.07, 0.07-0.09, and 0.09-0.10, and the sieve filtration rate is always the highest for this method among the several experimental methods. Thus, the designed method described in this paper is the most effective method for filtering silt-grade precipitates. The filtration rates are $42.2 \%$, $34.1 \%$, and $36.8 \%$ when the particle sizes are $0.05-0.07$, 0.07-0.09, and 0.09-0.10, respectively, with the method presented in literature [16], which was the lowest among the results of the several experimental methods tested. Therefore, the proposed method described in this paper is the most effective method for coarse particle filtering.

By analyzing the filtration performance of different grain sizes, it can be known that the removal rates of suspended matter reached $79.33 \%, 72.88,68.29$, and $65.75 \%$, respectively, when the filtration stages were less than $2 \mu \mathrm{m}, 3 \mu \mathrm{m}$, $4 \mu \mathrm{m}$, and $5 \mu \mathrm{m}$, respectively. Combined with the economic cost analysis, it was found that $2 \mu \mathrm{m}$ fine filtration was an ideal filtration level, but its economic cost was obviously 
increased. Using $3 \mu \mathrm{m}$ as the fine filtration stage, the removal rate of suspended matter only decreased by $6.45 \%$ compared with $2 \mu \mathrm{m}$ filtration stage, and the economic operation cost was controllable. With $4 \mu \mathrm{m}$ and above filtration stage, the removal rate of suspended solids will be reduced by more than $10 \%$, and the risk of tail water recharging blockage will be significantly increased. Therefore, it is suggested that under the principle of economic recharge, $2 \mu \mathrm{m} \sim 3 \mu \mathrm{m}$ filtration level should be used as the fine filtration equipment. According to the domestic experience of installing a set of coarse and fine filtration equipment for every $20 \mathrm{~m}^{3}$ tail water, it is recommended to adopt the ground equipment scheme of more than 5 sets of coarse and fine filtration equipment in parallel to achieve the effect of efficient recharge for the amount of more than $100 \mathrm{~m}^{3}$.

\section{Conclusion}

(1) The innovation of this paper is to analyze the static compatibility of raw water and hot storage tail water under different mixing ratios and to simulate the precipitation amount of precipitated minerals, so as to determine the test standard of efficient recharging effect of hot storage tail water

(2) Based on the filtration performance comparison experiment of different grain sizes and considering the principle of economic recharging, it is recommended to use $2 \mu \mathrm{m} \sim 3 \mu \mathrm{m}$ filtration stage as the fine filtration equipment

(3) Based on the experience of domestic filtration equipment, it is suggested to adopt the ground equipment scheme with more than 5 sets of coarse and fine filtration devices in parallel for the recharge volume of more than $100 \mathrm{~m}^{3}$, so as to achieve the effect of efficient recharge of hot storage tail water

\section{Data Availability}

The data supporting the results of our study are included within the manuscript.

\section{Conflicts of Interest}

The authors declare that they have no conflicts of interest.

\section{Acknowledgments}

This work was financially supported by the National Natural Science Foundation of China (51874240) and Key Research and Development Plan of Shaanxi Province (2020KW-027).

\section{References}

[1] Q. Yang and M. C. Chen, "Development obstacles of new energies in China and countermeasures: a review on global current situation," Journal of the earth, vol. 31, no. 5, pp. 759-767, 2010 .
[2] X. Wang, C. Liu, S. Chen, L. Chen, K. Li, and N. Liu, "Impact of coal sector's de-capacity policy on coal price," Applied Energy, vol. 265, article 114802, 2020.

[3] Z. Li, S. G. Liu, W. T. Ren, J. J. Fang, Q. H. Zhu, and Z. L. Dun, "Multiscale laboratory study and numerical analysis of waterweakening effect on shale," Advances in Materials Science and Engineering, vol. 2020, 14 pages, 2020.

[4] C. Zhu, M. He, M. Karakus, X. Cui, and Z. Tao, "Investigating toppling failure mechanism of anti-dip layered slope due to excavation by physical modelling," Rock Mechanics and Rock Engineering, vol. 53, no. 11, pp. 5029-5050, 2020.

[5] Z. F. Duan, F. L. Li, L. Gong, Y. H. Yang, and X. Y. Li, "Geothermal development well spacing patterns based on hydrothermal coupled modeling in oil-gas bearing areas," Natural Gas Industry, vol. 40, no. 10, pp. 156-162, 2020.

[6] M. C. He, B. Liu, L. H. Yao, and N. X. Xu, "Study on the theory of seepage field for geothermal single well reinjection," Acta Energiae Solaris Sinica, vol. 24, no. 2, pp. 197-201, 2003.

[7] J. L. Zhu, X. M. Zhu, and H. Y. Lei, “Analysis of impact of pressure compensation between geothermal wells on rejection efficiency," Acta Energiae Solaris Sinica, vol. 33, no. 1, pp. 56-62, 2012.

[8] V. U. Stefansson, "Geothermal reinjection experience," Geothermics, vol. 26, no. 1, pp. 99-139, 1997.

[9] C. Zhu, X. D. Xu, W. R. Liu et al., "Softening damage analysis of gypsum rock with Water immersion time based on laboratory experiment," IEEE Access, vol. 7, no. 7, pp. 125575$125585,2019$.

[10] X. L. Liu and J. L. Zhu, "A study of clogging in geothermal reinjection wells in the Neogene sandstone aquifer," Hydrogeology \& Engineering Geology, vol. 36, no. 5, pp. 138-141, 2009.

[11] D. L. Gallp, "Aluminum silicate scale formation and inhibition (1): scale characterization and laboratory experiments," Geothermics, vol. 26, pp. 483-499, 1997.

[12] E. J. Mackay, Midekkubg of In-Situ Scale Deposition: The Impact of Reservoir and Well Geometries and Kinetics Reaction Rates, Oilfield Scaling Symposium, Aber Deen, 2002.

[13] H. Y. Pan, D. Yin, N. Jiang, and Z. Xia, "Crack initiation behaviors of granite specimens containing crossing-double-flaws with different lengths under uniaxial loading," Advances in Civil Engineering, vol. 2020, Article ID 8871335, 13 pages, 2020.

[14] Z. Li, H. Zhou, D. Hu, and C. Zhang, "Yield criterion for rocklike geomaterials based on strain energy and CMP model," International Journal of Geomechanics, vol. 20, no. 3, article 04020013, 2020.

[15] J. Y. Wang, S. B. Hu, Z. H. Pang et al., "Estimate of geothermal resources potential for hot dry rock in the continental area of China," Science \& Technology Review, vol. 2, no. 3, pp. 3-9, 2012.

[16] X. D. Zhang, Y. Y. Wu, E. C. Zhai, and P. Ye, "Coupling analysis of the heat-water dynamics and frozen depth in a seasonally frozen zone," Journal of Hydrology, vol. 593, article 125603, 2020.

[17] Z. H. Pang, Y. L. Kong, J. M. Pang, and S. B. Wang, "Geothermal resources and development in Xiongan New Area," Bulletin of the Chinese Academy of Sciences, vol. 11, pp. 1224-1230, 2017.

[18] J. E. Oddo and M. B. Tomsnon, "Simplified calculation of $\mathrm{CaCO}_{3}$ saturation at high temperatures and pressures in brine solutions," Journal of Petroleum Technology, vol. 34, pp. 47-53, 1982. 
[19] Z. Li, H. X. Liu, Z. L. Dun, L. W. Ren, and J. J. Fang, "Grouting effect on rock fracture using shear and seepage assessment," Construction and Building Materials, vol. 242, article 118131, 2020.

[20] Z. H. Zhao, G. H. Liu, X. F. Tan, and P. P. Zhang, "Theoretical model of geothermal tail water reinjection based on the equivalent flow channel model," Hydrogeology \& Engineering geology, vol. 44, no. 3, pp. 47-53, 1982.

[21] Z. Y. Ma, C. Hou, L. A. Xi, P. Q. Yuan, H. Yan, and C. X. Song, "Reinjection clogging mechanism of used geothermal water in a super-deep-porous reservoir," Hydrogeology \& Engineering geology, vol. 40, no. 5, pp. 134-139, 2013.

[22] Q. Meng, H. Wang, M. Cai, W. Xu, X. Zhuang, and T. Rabczuk, "Three-dimensional mesoscale computational modeling of soil-rock mixtures with concave particles," Engineering Geology, vol. 277, article 105802, 2020.

[23] Z. T. Liu, S. Liu, W. H. Song, X. C. Yang, and Q. D. Zhou, "Change chaaracteristics of geothermal field for geothermal return water reinjection of sandstone reservoir in the northern Shangdong," Acta geologica sinica, vol. 93, Supplement 1, pp. 150-157, 2019.

[24] M. X. Zeng, C. X. Ruan, Y. B. Zhao, and G. H. Tian, "Connect test between karst cranny reservoir pumping well and injection well," Geology and Prospecting, vol. 44, no. 2, pp. 105-109, 2008.

[25] J. M. Pang, Z. H. Pang, Y. L. Kong, L. Luo, Y. C. Wang, and S. F. Wang, "Interwell connectivity in a karstic geothermal reservoir through tracer tests," Chinese Journal of Geology, vol. 49, no. 3, pp. 915-923, 2014.

[26] Y. J. Li, Study on Geothermal Reinjection of Tracer Technology and Simulation of Thermal Energy Storage, Chinese Academy of Geological Sciences, Beijing, 2010.

[27] S. F. Wang, J. R. Liu, P. Lin et al., "A study of reinjection experiment and tracer test in a karst geothermal reservoir," Hydrogeology \& Engineering Geology, vol. 40, no. 6, pp. 129-133, 2013. 